\title{
EFFECT OF DIFFERENT IMPLANTS POSITIONS AND NUMBER ON RESISTANCE OF MANDIBULAR POLYURETHANE REPLICAS TO FRACTURE
}

\author{
Basem T. Fadl ${ }^{1}{ }^{*} B D s$ Mohamed S. El-Attar 2 PhD, Ingy S. Soliman 3 PhD, Mohamed A. Abu Saied 4, \\ PhD.
}

ABSTRACT

INTRODUCTION: Many case reports and retrospective studies related implant placement to mandibular weakness and fracture. OBJECTIVES: This study aimed to investigate the effect of number and positions of dental implants on structure integrity of completely edentulous mandible.

MATERIAL AND METHODS: Thirty-two synthetic edentulous polyurethane mandibles were divided in 4 groups: First group (I) was unaltered eight fully intact replicas representing control group acting as reference. Second group (II) was eight replicas where only single symphysial implant was placed representing single implant group. Third Group (III) was eight replicas with inserted double implants in canine area representing double implant group, while fourth group (IV) was eight replicas with inserted triple implants (two implants in premolar area, one implant in symphysis) representing triple implant group. Vertical loads were simulated by universal testing machine under conditions simulating trauma, with a compression force acting laterally on the ramus of the mandible with displacement rate up of $5 \mathrm{~mm} / \mathrm{min}$ until failure. The primary outcome variable was maximum load to failure. Other outcome variables were Fracture locations and displacement to failure. Scanning electron microscope was utilized to evaluate the changes in the implant surfaces in fracture sites.

RESULTS: the results of this study revealed that there were significant differences in Maximal failure loads and fracture location across all groups [P = $0.02, P<0.0001$, respectively].

CONCLUSION: It was assumed from this study that placement of dental implant in canine positions disturbed structure integrity of intact mandibles and acted as point of weakness.

KEYWORDS: Implant Positions, Implant overdenture, Fracture Resistance, Trauma, Mandibular fracture.

RUNNING TITLE: Mandibular structure integrity after Implant placement.

1Master researcher, Removable Prosthodontic Department, Faculty of Dentistry, Alexandria University, Alexandria, Egypt.

2 Professor of Prosthodontics, Removable Prosthodontic Department, Faculty of Dentistry, Alexandria University, Egypt.President of Alexandria Oral Implantology Association (AOIA), Egypt.

3 Lecturer of Prosthodontics. Removable Prosthodontic Department Faculty of Dentistry Alexandria University, Egypt.

4 Associate Professor Polymer Materials Research Department, Advanced Technologies, and New Materials Research Institute (ATNMRI), City of Scientific Research and Technology Applications.

*Corresponding Author

E-mail: basemmfadll@yahoo.com

\section{INTRODUCTION}

Elderly people are prone to trauma correlated with agespecific illness such as cardiovascular disease ,fatigue, arthritis , slow reflexes and vision loss (1). Though the mandible was well identified to be the most rigid bone in craniofacial structure, Yamamoto et al stated that fractures in older patients with craniofacial fractures occurred mostly in the mandible (2). Moreover, the mandible becomes weaker and more susceptible to fracture with age due to tooth loss and bone resorption (3). In The End of resorption, the edentulous portion of the mandible will have a great atrophy related to the mandibular body regions and the symphysis facing possible fractures in those sites $(4,5)$. The current proof reveals that the replacement of the edentulous mandible with a traditional complete denture is not the most suitable prosthodontic therapy of first choice (6). Moreover, Implant assisted Overdentures are regarded a preferable gold

standard choice for rehabilitation using two endosseous implants, which reduce the cost of treatment and provide greater satisfaction due to retentive functional dentures $(7,8)$. However, the use of two- implant assisted mandibular overdentures had some limitations. For illustration, it is not recommended in some instances which include patients with V-shape or severely resorbed ridges with high occlusal force and if more retention is needed due to high muscles attachments $(9,10)$.

The two implant assisted overdenture under the vertical loading of the anterior region showed more denture rotational movement and additional stress in the abutments decreasing their ability to chew compared to one-and three-implant assisted overdentures , and that's why an additional symphysial implant can be added in 
patients with two implant-assisted overdentures who complain about rotational movement of the denture preventing overdenture rotation around fulcrum line $(11,12)$.

A current design that utilizes only single symphysial implant to retain the mandibular over denture is emerging which offers an alternative cost-effective treatment for patients with limited financial income (13).

While a significant literature review demonstrated satisfying results of overdenture treatment with single implant by evaluating some variables like implant life expectancy, marginal bone loss, improved patient satisfaction and life quality (14), another clinical research reported some problems associated with treatment options for single implant overdenture such as a potential risk of vascular damage in elderly people as The lingual foramen is located in the symphysis (15).

Though Mandibular fractures resulting from implant placement in atrophic mandible are a rare complication (16), Numerous case reports and retrospective studies had related mandibular fractures with implant placement (17-19). Thus, it is possible that implant placement in edentulous mandible may further compromise the structural integrity of the jaw, with an associated increase in the risk of fracture upon trauma.

While many studies had focused on the topic of implant-assisted overdentures in the edentulous mandible, few rare studies related implants cavity preparation and placement to mandible weakening. Therefore, this research was conducted to compare in consistent sample the differences in fracture resistance, maximum failure load, maximum displacement and fracture locations between fully intact mandibular replicas and replicas where one, two or three implants were inserted.

\section{MATERIAL AND METHODS}

The protocol of this study was reviewed and approved Research Ethics Committee in Faculty of dentistry, Alexandria University, Egypt. The study was an in-vitro (laboratory based) research which compared and evaluated the effect of different implant positions and number on the structure integrity and fracture resistance of mandibular polyurethane replicas. The study was conducted in city of scientific research in new Borg Arab, Alexandria, Egypt.

\section{Sample size:}

The sample size was calculated based on a previous study aimed to evaluate maximum displacement and load failure between intact mandibular replicas and replicas from which blocks were taken at the symphysis or the ramus. Al-Sabbagh $\mathrm{M}$. et al., (2017) reported that there were statistically significant differences in maximal failure load between groups $(\mathrm{p}=0.0008)$ (20). Their findings resulted in standardized effect size (d) of 1.291 of maximal load (N) as a primary outcome, (large-sized standardized effect size) resulted in the minimal required sample size of $\mathbf{8}$ specimens per group (number of groups $=\mathbf{4}$ ), (total sample size $=32$ specimens) (21). A power of $80 \%$ and level of significance $95 \%(\alpha=0.05)$ and a power of $90 \%$ was adopted. The sample size was analyzed using $\mathrm{G}^{*}$ Power version 3.1.9.2 (22).

This study used synthetic edentulous mandibular polyurethane replicas (C-Tech, Italy). These synthetic replicas were chosen for this study to avoid many variables related to cadaveric edentulous mandibles and animal bone such as age, hormonal, environmental, and nutritional factors (23).

\section{Study Design:}

Thirty-two synthetic edentulous polyurethane replicas were divided in 4 groups: First group (I) was unaltered eight fully intact replicas representing control group acting as reference. Second group (II) was eight replicas where only single symphysial implant was placed representing single implant group. Third Group (III) was eight replicas with inserted double implants in canine regions representing double implant group while fourth group (IV) was eight replicas with inserted triple implants (two implants in premolar area and one implant in symphysis) representing triple implant group.

The replicas had two different densities where they had a dense external layer that mimics outer cortical bone as well as a spongy inner core that mimics cancellous bone (23). Only one test was conducted on each atrophic mandible because each one was tested to failure in loading.

Although when human bone substitutes are used, no direct connection with clinical scenarios can be made. it is worth mentioning that Such replicas can recognize patterns in biomechanical studies(20). However, before these tests, no severe atrophic mandibular replicas were commercially available on the market. Only mild atrophic replicas with a vertical height of less than $20 \mathrm{~mm}$ were available (24).

\section{Fabrication of Completely Limited Computerized Surgical Guide for Implant Placement:}

The implant exact location was necessary for this study. Therefore, The use of interactive computer-assisted surgical guide had facilitated the placement of implants in accurate positions especially when critical bone mass existed as a result of atrophy (25). To construct computerized completely limited surgical guide, polyurethane replica was marked with crest of ridge lines and any major undercut was blocked out with pink modelling wax(Cavex ,Holland By, The Netherlands) leaving 0.02 inches undercut to be used for retention .A completely adapted record block made of Cold cure acrylic resin(Acrostone plus, Acrostone, Egypt) was fabricated from right mental foramen area to left mental foramen area .

The width of anterior acrylic teeth (Acrostone, Acrostone, Egypt) were selected according the ratio between intercondylar width and the mandibular inter-canine width (5.1:1) and arranged on crest of ridge(26). The record blocks were flasked and processed in slow heat curing cycle $70^{\circ} \mathrm{C}$ for $7-9$ hours than $100^{\circ} \mathrm{C}$ for $30 \mathrm{~min}$. The denture was finished and polished to be scanned.

Specific double-scanning technique was used for high-level resolution digitization of the radiographic guide. In this technique, the denture was marked with small balls of gutta percha (Conform Fit Gutta-Percha Points for Pro Taper Gold, Dentsply Sirona, USA) at different heights acting as radiopaque markers. The denture was scanned with Cone beam computed tomography (Sordex Scanora 3Dx, USA) twice. The First scan was with polyurethane replica while the second scan was for the denture only. Both scans were overlaid on each other resulting 
in a three-dimensional (3D) model of the polyurethane replicas and the marked denture. Cone Beam CT were used to generate multiple cross-sectional and 3D images of the scanning. A cone beam computed tomography images were obtained in DICOM format (Digital Imaging and Communications in Medicine) which was transferred to planning software (Blue Sky Bio VERSION 4.5 Libertyville, USA) that provided really (3D) model for designing implant positions and size.

In planning software, Virtual Implant locations were selected in symphysis area, canine area and premolar area. All virtual implants were placed inter-foraminally with equal bone remaining to the labial and lingual margins $(1 \mathrm{~mm}$ from both margins) .virtual implants were designed to be 3.5 in diameter and $11 \mathrm{~mm}$ in length .After the positions of implants were accepted in the virtual guide, the virtual implant guide was exported to selective laser sintering (SLS) prototyping machine (Form 3, Form Labs, USA) for surgical guide construction.

\section{Fabrication of Metallic Jigs:}

Upper and lower metallic jigs were fabricated from aluminum copper alloy particularly for this study to stabilize the replica during testing procedure and act as a compression arm. Every metallic jig has two poles. one pole had specific diameter(29,1mm) to fit into the opening of universal testing machine, while the other pole $(10 \mathrm{~mm}$ in diameter) had corresponding inclination to fit against the outer surface of the ramus. Cold cure acrylic resin (Acrostone, Egypt) was added to the pole facing the ramus to have more adaptation and prevent slippage during testing procedure (Fig.1).

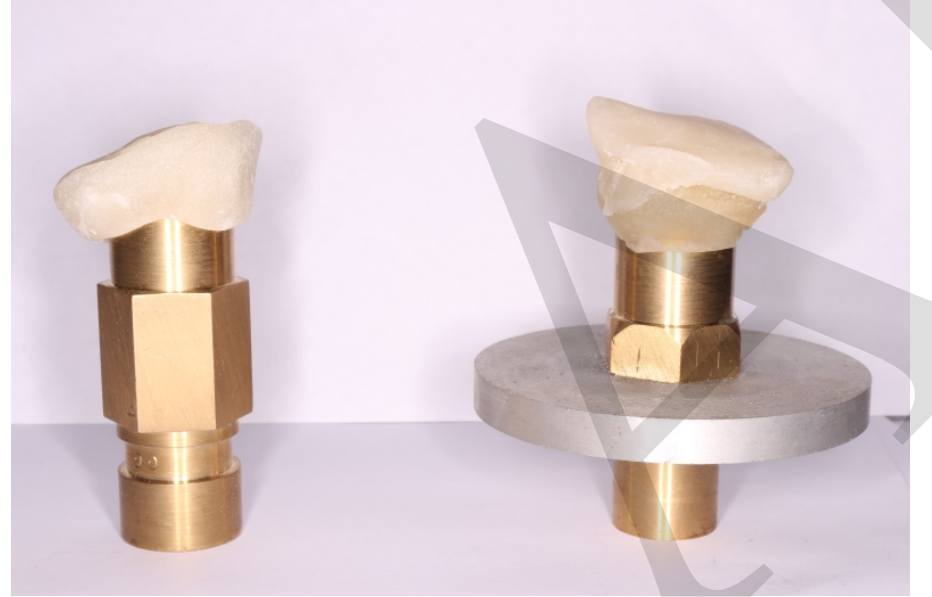

Figure 1: Custom Made Metallic Jigs

\section{Mandible Preparation:}

The prefabricated 3D printed surgical guide was used to place implants in single, double and triple implant group, according to the drill sequence of the guided surgery kits (pilot drill. Intermediate drill, final drill) (C-Tech, Italy). The printed surgical guide was fixed to the polyurethane replicas using fixation screw. The positions of fixation screws were designed to be away from implant sites. Bone level implants (C-Tech, Italy) $3.5 \varnothing, 11 \mathrm{~mm}$ in length were inserted in the previous mentioned positions in different groups and torqued to 25 Newton-centimeter (N.cm) to have accepted primary stability leaving $1.5 \mathrm{~mm}$ labial and palatal bone around inserted implants.

\section{Mandible Testing:}

Upper and lower custom made metallic jigs were secured over the ramus to avoid slippage during testing procedures .Vertical loads were simulated by universal testing machine (AG-IS Shimadzu, Kiyamachi-Nijo, Kyoto, Japan) under conditions simulating trauma, with a compression force acting laterally on the ramus of the mandible with displacement rate up to 5 $\mathrm{mm} / \mathrm{min}$ until failure (Fig.2).

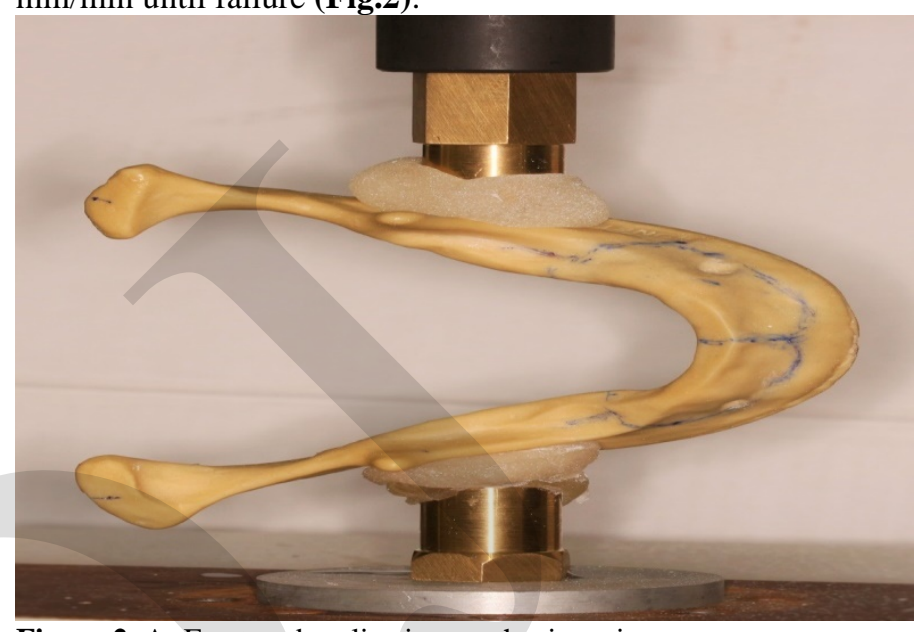

Figure 2. A Fractured replica in symphysis regions

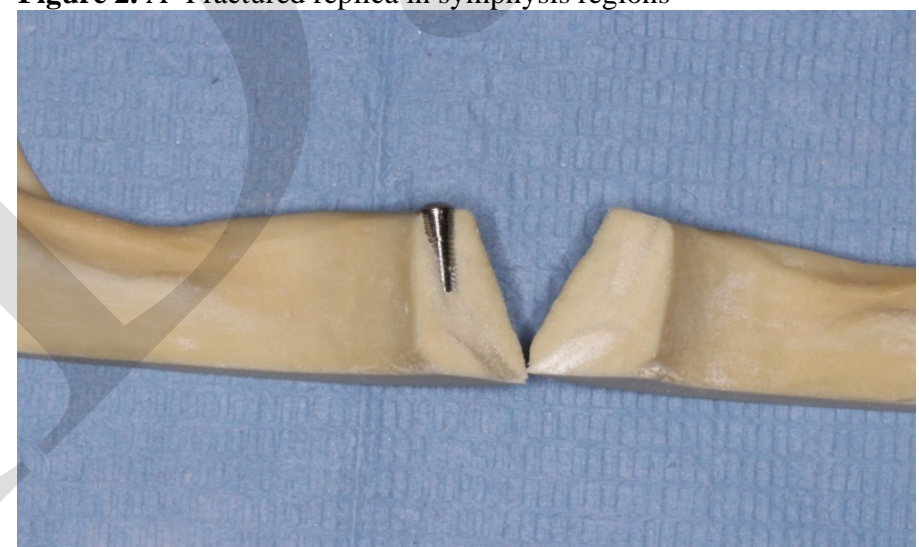

Figure 2. B : Fractured replica in symphysis regions

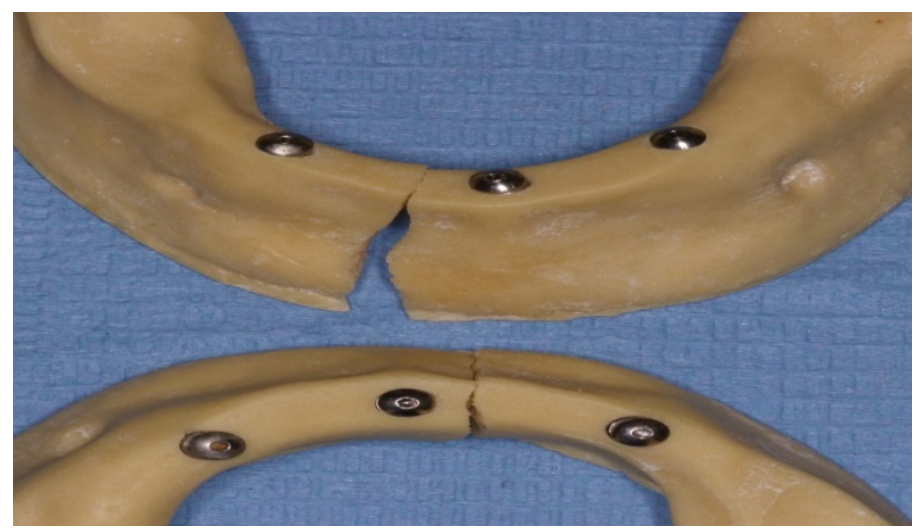

Figure 2. C : Fractured replicas in Para symphysis regions.

Fracture locations were collected and categorized to the following anatomical sites: Right mental foramen , Para symphysis area near any positioned implant, symphysis at 
symphysial implant, Force (in newtons) and displacement (in millimeters) were measured at increments of $1 \mathrm{~N}$ and $0.5 \mathrm{~mm}$, respectively. Data were sent to Microsoft Excel for analysis. The data were analyzed by comparing maximum failure load, failure displacement and fracture locations between the unaltered mandibles and the implant samples.

\section{Scanning Electron Microscopy Sample Preparation and Imaging:}

All implants in fracture sites were imaged with scanning electron microscope (JSM-IT500 In Touch Scope ${ }^{\mathrm{TM}}$ Sem Series, JEOL Inc, Japan). Scanning electron microscopes (SEM) could magnify a sample 20-130,000× with higher quality resolution and perfect details. The SEM evaluation was conducted on buccal and lingual aspects of the placed implants at the level of the upper, middle, and apical thirds of the implant to detect any alterations or microcracks resulting from replica fracture.

Implant samples was coated with a conductive layer to improve the image quality. A sputter coater (Spi Module, Eden Instruments, France) used argon ions to coat the surface of the sample with golden atom to produce a conductive thin layer coating. The coated implant samples were inserted into SEM to be Scanned by technician blinded to the study groups on the buccal and palatal aspects of the implant.

\section{Statistical Analysis:}

Normality was checked using descriptive statistics, plots (histogram and box plot) and Kolmogorov Smirnov test. Maximum force and displacement were presented using mean and standard deviation. Frequencies and percentages were used to present fracture location. Difference in maximum force and displacement among the study groups was assessed using One Way ANOVA test. Chi square test was applied to detect differences in fracture location. Significance level was set at $(\mathrm{p} \leq$ 0.05). Data was analyzed using IBM SPSS statistical software (version 25).

\section{RESULTS}

Data was collected accurately for all tested 32 replicas in all groups. There wasn't any missing samples or data during testing procedures. Regarding to the effect of implant positions and number on fracture resistance of polyurethane replicas , the results of this study revealed that the Control group (fully intact replicas) experienced the higher maximum failure load at 158.11(47.00) $\mathrm{N}$ while double implants group was the lowest failure load at $\mathbf{8 2 . 9 0 ( 3 5 . 3 3 ) ~} \mathrm{N}$.The nearest group to control group 158.11(47.00) $\mathrm{N}$ was single implant group at 126.26(60.61) $\mathrm{N}$ followed by triple implants group at 112.43(40.47) N (Fig.3). There were significant differences in Maximal failure loads across all groups $(\boldsymbol{P}=\mathbf{0 . 0 2})$ .Although Control group were significantly more likely to break at a higher maximal load than double implants group $(\boldsymbol{P}=\mathbf{0 . 0 1})$, Control group were insignificantly more likely to fail at maximal load than single and triple implant group $(\boldsymbol{P}=\mathbf{0 . 5 3}, \boldsymbol{P}=\mathbf{0 . 2 3}$, respectively) Table (1). Moreover, the results of this study revealed that there were insignificant differences in maximal displacement across all groups $(\boldsymbol{P}=\mathbf{0 . 0 9})$.

Break locations were significantly different across all groups $(\boldsymbol{P}<\mathbf{0 . 0 0 0 1})$. Most Control group (intact mandibles) broke along the right mental foramen $(66.7 \%)$, while most Double implants group broke along the Para symphysis at implant site
(71.4\%). The majority of single implant group and triple implant group broke along symphysis at symphysial implant (77.8\%,55.6\% respectively) (Fig. 4). In pair wise comparison between the groups with respect to the fracture locations, control group was significantly more like to break in different fracture locations than single and double implant group ( $\boldsymbol{P}=\mathbf{0 . 0 4}, \boldsymbol{P}=\mathbf{0 . 0 1}$, respectively). Moreover, single implant group was significantly more likely to break at implant site in symphysis than double and triple implant group $(\boldsymbol{P}=\mathbf{0 . 0 4}, \boldsymbol{P}=\mathbf{0 . 0 1}$ respectively) Table (1).

Table 1 . Maximum Load and Fracture Locations Results

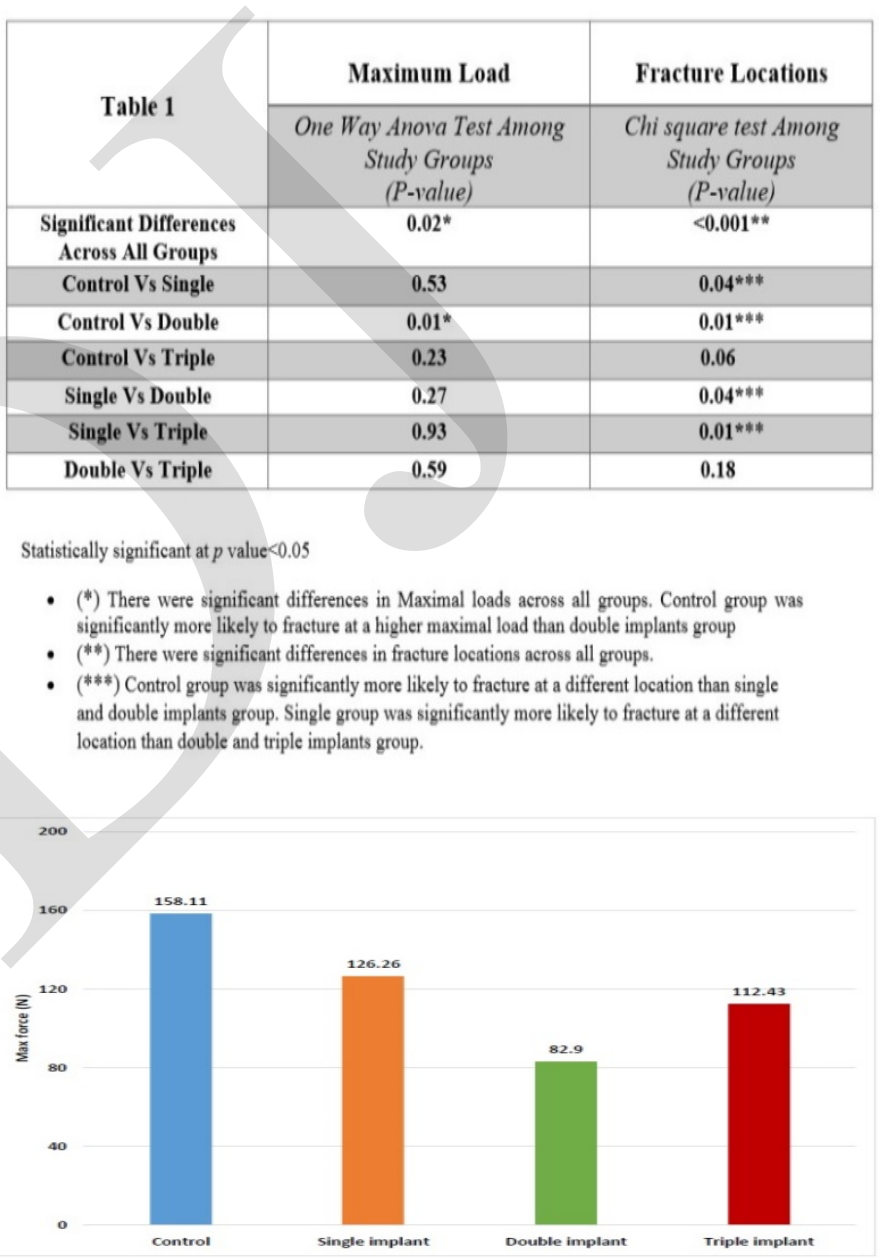

Figure 3 Maximum force among the study groups

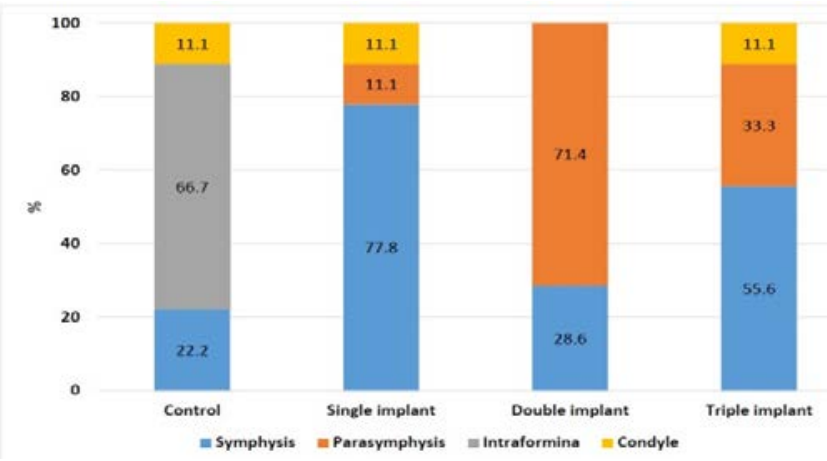


Figure 4: Comparison of the rate of fracture locations among the study groups

Pictures of scanning electron microscope indicated that all the implants surfaces were surrounded by polyurethane foam particles anchored to the implant surface. At low magnification, $71.4 \%$ of the scanned implants in single implant group revealed multiple Longitudinal microcracks extending from crest modules to implant body. At higher magnification, it was found that $33.4 \%$ of the scanned implants in double implant group and $60 \%$ of the scanned implants in triple implant group had multiple longitudinal microcracks at implant crest module and implant body (Fig .5).

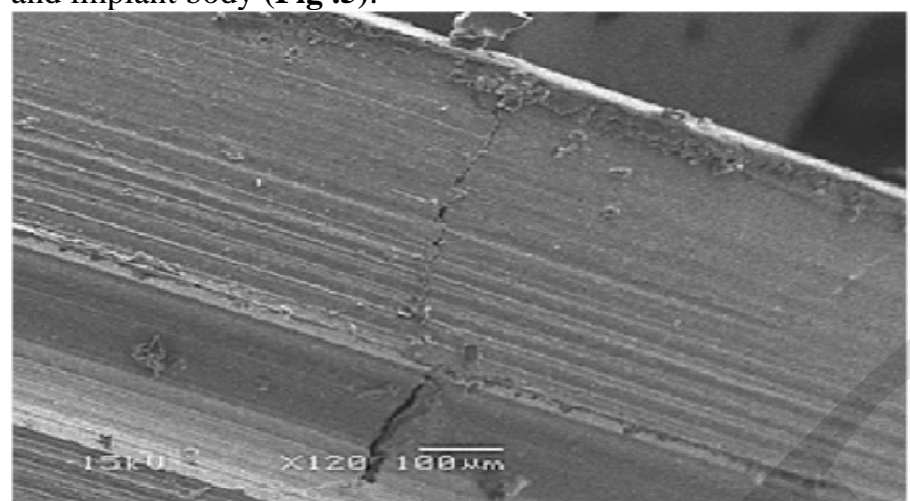

Figure 5 :Scanning electron microscopy (SEM) pictures of implant surface at fracture site. At low magnification (120×) of implant surface in single implant group after failure, picture show longitudinal microcrack extending from implant crest module to the body

\section{DISCUSSION}

The results of the present study revealed that the configuration of different positions and number of implants had a significant effect on the structure integrity of atrophic mandibles to resist lateral traumatic load and the mandibular replicas where implants had been placed required less force to fracture than intact mandibular replicas. Therefore, the null hypothesis that the force required to break the intact mandibles would be the same as that required to break the implant samples was rejected. Regarding the effect of implant positions and number on fracture resistance of polyurethane replicas, the results of this study revealed that there were significant differences in Maximal loads across all groups $(\boldsymbol{P}=\mathbf{0 . 0 2})$. The findings of the present study showed that intact replicas resist lateral traumatic load and preserved its structure integrity than other groups with inserted implants. Moreover, the group with double implants in canine regions lost structure integrity earlier with less load than any other group.

It is worth mentioning that the anterior regions of the mandible usually have more compact and dense trabeculae relative to their posterior regions. In a four-scale classification, D4 means that the soft bone is located predominantly in the posterior maxillae and that the more dense compact bone (D1) is often found in the anterior mandible (27). In addition , Jonsson et al (28) indicated that there was a marked association between trabecular density and fracture risk. In other word, the trabecular pattern was a highly significant predictor of future fracture risk so that dense compact bone in anterior mandible acts as a protector from fracture. That's why, in this study, preparing implants cavities by removing dense compact bone from canine regions or symphysis greatly disturbed the structure integrity of the mandibles and weakened it. The lowest fracture resistance of replicas with double implants in the present study can be explained by the number of cavities where dense compact bone was removed.

According to Kan et al (29) inter-implant distance play important role in frontal trauma. Increasing the inter-implant distance decrease the fracture resistance of atrophic mandible. Moreover, they recommended placement of implants in the lateral incisor area instead of the canine area because of increasing in inter-implant distance.

Regarding to the effect of implant positions and number on fracture locations of polyurethane replicas, the results of this study revealed that break locations were significantly different across all mandible groups $(\boldsymbol{P}<\mathbf{0 . 0 0 0 1})$. The findings of the present study showed that the fractures locations in intact replicas were in right mental foramen area while in other groups with implant cavities the fracture locations were in implant sites in implant group.

Since, In 1961,Huelke (30) analyzed Mechanics in relation to mandibular fractures and concluded that Elevated tensile strain and stress patterns encircled bony defects, such as mental foramen. It is worth mentioning that there was a high correlation between area of bone discontinuity that concentrates stress in a very small area and mandibular fractures.

Furthermore, Morris et al (31) reported that Several sites of stress concentration were observed in non-homogeneous materials such as bone due to the irregularity of the internally and externally structures such as, mental foramen. Besides, Weiss predicted with great exactness where mandibular fracture would occur under known static loading conditions by locating high tensile strain patterns in area of stress concentration (32). This could explain the results of the present study why most of the fractures locations in intact replicas were in right mental foramen area.

On other hand, it was concluded that after implant placement, mandible suffer from tension and compression forces during function. That Tension patterns continue to stretch the bone acting as a point of weakness, that's why Many researchers considered the mandible to be farther sensitive to tensile forces than to compressive forces $(30,32,33)$.

In biomechanical study by Steiner et al (34), all mandibles were experienced with biting force. The study found that the mean failure load in control group with unaltered replicas was noticeably higher than in any of the groups with prepared implant cavities and all implant groups experienced fracture in implant sites. In brief, there was an increased risk of fracture of the mandible resulting from cavities preparation for implants which acted as an area of weakness. Although the previous study was discussing mandibles fracture with biting force instead of trauma, it could also support the results of the present study why most of the fractures locations in implants group were in implant sites. 
In 1990,Mason et al (35) investigated many case reports about placement of endosseous implants in sever atrophic mandibles and its relation to mandibles fracture. They reported that the implant that has not been Osseointegrated acts as a site of stress concentration and ultimately an area of weakness. Moreover,it was reported that the stress distribution pattern was unfavorable around the implant till dense lamellar bone replaces soft woven bone (36-38).Therefore, an implant that was completely Osseointegrated having great fit to the bony walls, didn't concentrate any stresses during the unloaded healing period.

Another biomechanical study showed that higher stress levels occur where implants came directly in contact with dense cortical bone (39). This biomechanical study(39) could support two important results in the present study: Firstly, most of fractures locations in triple implants group occurred near or in symphysial implant sites instead of fracture at implant site in premolar positions because implants in those positions are surrounded by spongious bone which absorbed traumatic force (40). Secondly, the fracture resistance of double implants groups was experimentally lower than triple implants group because all implants in double implants group were in direct contact with dense cortical bone in canine regions.

This research had certain limits that should be experimented in the future studies. Absence of severe atrophic mandible in the market and the ethical issues related to using cadaveric mandibles were the main limits as most published case reports related severe atrophic mandibular fracture to implant placement .However, using mild atrophic mandible in this study could identify biomechanical patterns of atrophic mandibles just before failure. Though there are no strong clinical associations, the biomechanical patterns and results described in this study raised some clinically relevant questions .Do we need to increase number of implants in atrophic mandibles on account of mandible structure integrity to gain high retention?, What about placing implant more posteriorly in posterior spongy bone instead of anterior compact bone?. Does the placement of double implants in canine regions still be the gold standard for implant assisted overdenture? and if yes will it be valid to atrophic mandibles? Can we advise the patients to avoid any traumatic situation during healing and osseointegration period? Besides this study, many future studies are needed to answer all those questions. Also, retrospective studies and case reports could help considerably.

\section{CONCLUSION}

Within the limitations of the present research, it was lateral horizontal trauma. concluded that the number and positions of dental implants had major role in predicating fracture resistance of atrophic mandible to withstand lateral trauma .likewise, placement of dental implant may be acted as point of weakness disturbing structure integrity of intact mandibles in addition to reducing its ability to resist lateral traumatic load. Moreover, implant sites could be expected to be the future fracture locations if atrophic mandibles were exposed to lateral horizontal trauma

\section{CONFLICT OF INTEREST}

The authors declare that they have no conflicts of interest

\section{REFERENCES}

1. Kim TG, Chung KJ, Lee JH, Kim YH, Lee JH. Clinical outcomes between atrophic and nonatrophic mandibular fracture in elderly patients. J Craniofac Surg. 2018;29(8):E815-8.

2. Yamamoto K, Matsusue Y, Murakami K, Horita S, Sugiura T, Kirita T. Maxillofacial fractures in older patients. J Oral Maxillofac Surg [Internet]. 2011;69(8):2204-10. Available from: http://dx.doi.org/10.1016/j.joms.2011.02.115

3. Emam HA, Ferguson HW, Jatana CA. Management of atrophic mandible fractures: an updated comprehensive review. Oral Surg. 2018;11(1):79-87.

4. CAMPBELL RL. A comparative study of the resorption of the alveolar ridges in denture-wearers and non-denturewearers. J Am Dent Assoc. 1960;60(2):143-53.

5. Marciani RD. Invasive management of the fractured atrophic edentulous mandible. J Oral Maxillofac Surg. 2001;59(7):792-5.

6. Feine JS, Carlsson GE, Awad MA, Chehade A, Duncan WJ, Gizani S, et al. The McGill consensus statement on overdentures. Mandibular two-implant overdentures as first choice standard of care for edentulous patients. Montreal, Quebec, May 24-25, 2002. Int J Oral Maxillofac Implants [Internet]. 2002;17(4):601-2. Available from: http://www.ncbi.nlm.nih.gov/pubmed/12182304

7. Thomason JM, Kelly SAM, Bendkowski A, Ellis JS. Two implant retained overdentures - A review of the literature supporting the McGill and York consensus statements. J Dent. 2012;40(1):22-34.

8. Cardoso RG, Melo LA de, Barbosa GAS, Calderon PDS, Germano AR, Mestriner W, et al. Impact of mandibular conventional denture and overdenture on quality of life and masticatory efficiency. Braz Oral Res. 2016;30(1):e102.

9. Sadowsky SJ. Mandibular implant-retained overdentures: a literature review. J Prosthet Dent. 2001;86(5):468-73.

10. Mericske-stern R, Piotti M, Sirtes G. 3-D in vivo force measurements on mandibular implants supporting overdentures. A comparative study. Clin Oral Implants Res. 1996;7(4):387-96.

11. Geckili O, Bilhan H, Mumcu E. Clinical and radiographic evaluation of three-implant--retained mandibular overdentures: A 3-year retrospective study. Quintessence Int (Berl). 2011;42(9).

12. Liu J, Pan S, Dong J, Mo Z, Fan Y, Feng H. Influence of implant number on the biomechanical behaviour of mandibular implant-retained/supported overdentures: A three-dimensional finite element analysis. J Dent. 2013;41(3):241-9.

13. Mahoorkar S, Bhat S, Kant R. Single implant supported mandibular overdenture: A literature review. J Indian Prosthodont Soc. 2016;16(1):75.

14. Alsabeeha N, Payne AGT, De Silva RK, Swain M V. 
Mandibular single-implant overdentures: A review with surgical and prosthodontic perspectives of a novel approach. Clin Oral Implants Res. 2009;20(4):356-65.

15. Mraiwa N, Jacobs R, Van Steenberghe D, Quirynen M. Clinical Assessment and Surgical Implications of Anatomic Challenges in the Anterior Mandible. Clin Implant Dent Relat Res. 2003;5(4):219-25.

16. Goodacre CJ, Kan JY, Rungcharassaeng K. Clinical complications of osseointegrated implants. J Prosthet Dent. 1999;81(5):537-52.

17. Luhr HG, Reidick T, Merten HA. Fractures of the atrophic mandible--a challenge for therapy. Fortschr Kiefer Gesichtschir. 1996;41:151-4.

18. Karlis V, Bae RD, Glickman RS. Mandibular fracture as a complication of inferior alveolar nerve transposition and placement of endosseous implants: A case report. Implant Dent. 2003;12(3):211-6.

19. Almasri M, El-Hakim M. Fracture of the anterior segment of the atrophic mandible related to dental implants. Int $\mathrm{J}$ Oral Maxillofac Surg. 2012;41(5):646-9.

20. Al-Sabbagh M, Romanos G, Price SR, Puleo DA, Robinson FG, Thomas M V. Resistance of Mandibular Polyurethane Replicas to Fracture after Removal of Blocks from the Symphysis and Ramus. Implant Dent. 2017;26(3):367-72.

21. Charan J, Biswas T. How to calculate sample size for different study designs in medical research? Indian J Psychol Med. 2013;35(2):121-6.

22. Faul F, Erdfelder E, Lang AG, Buchner A. G*Power 3: A flexible statistical power analysis program for the social, behavioral, and biomedical sciences. Behav Res Methods. 2007;39(2):175-91.

23. Bredbenner TL, Haug RH. Substitutes for human cadaveric bone in maxillofacial rigid fixation research. Oral Surg Oral Med Oral Pathol Oral Radiol Endod. 2000;90(5):574-80.

24. Luhr HG, Reidick T, Merten HA. Results of treatment of fractures of the atrophic edentulous mandible by compression plating: A retrospective evaluation of 84 consecutive cases. J Oral Maxillofac Surg. 1996;54(3):250-4.

25. Ruppin J, Popovic A, Strauss M, Spüntrup E, Steiner A, Stoll C. Evaluation of the accuracy of three different computer-aided surgery systems in dental implantology: Optical tracking vs. stereolithographic splint systems. Clin Oral Implants Res. 2008;19(7):709-16.

26. Qamar K, Shaikh IA, Naeem S. Relationship of the intercondylar width with mandibular inter-canine width. J Ayub Med Coll Abbottabad. 2013;25(1-2):191-3.

27. Misch CE. Bone classification, training keys to implant success. Dent Today. 1989;8(4):39-44.

28. Jonasson $\mathrm{G}$, Sundh V, Ahlqwist $\mathrm{M}$, Hakeberg $\mathrm{M}$, Björkelund C, Lissner L. A prospective study of mandibular trabecular bone to predict fracture incidence in women: A low-cost screening tool in the dental clinic. Bone. 2011;49(4):873-9.
29. Kan B, Coskunses FM, Mutlu I, Ugur L, Meral DG. Effects of inter-implant distance and implant length on the response to frontal traumatic force of two anterior implants in an atrophic mandible: Three-dimensional finite element analysis. Int J Oral Maxillofac Surg. 2015;44(7):908-13.

30. Huelke DF. Mechanics in the Production of Mandibular Fractures: A Study with the "Stresscoat" Technique. I. Symphyseal Impacts. J Dent Res. 1961;40(5):1042-56.

31. Morris JM. Fatigue fractures. Calif Med. 1968;108(4):268.

32. Weiss L. Static loading of the mandible. Oral Surgery, Oral Med Oral Pathol. 1965;19(2):253-62.

33. Halazonetis JA. The 'weak'regions of the mandible. $\mathrm{Br} \mathrm{J}$ Oral Surg. 1968;6(1):37-48.

34. Steiner T, Torsiglieri T, Rau A, Möhlhenrich SC, Eichhorn S, Grohmann I, et al. Impairment of an atrophic mandible by preparation of the implant cavity: a biomechanical study. Br J Oral Maxillofac Surg [Internet]. 2016;54(6):619-24. Available from: http://dx.doi.org/10.1016/j.bjoms.2016.03.013

35. Mason ME, Gilbert Triplett R, Van Sickels JE, Parel SM. Mandibular fractures through endosseous cylinder implants: Report of cases and review. J Oral Maxillofac Surg. 1990;48(3):311-7.

36. Cakarer S, Can T, Yaltirik M, Keskin C. Complications associated with the ball, bar and locator attachments for implant-supported overdentures. Med Oral Patol Oral Cir Bucal. 2011;16(7):e953-9.

37. Hedia HS. Stress and strain distribution behavior in the bone due to the effect of cancellous bone, dental implant material and the bone height. Biomed Mater Eng. 2002;12(2):111-9.

38. Chang MC, Ko CC, Liu CC, Douglas WH, DeLong R, Seong WJ, et al. Elasticity of alveolar bone near dental implant-bone interfaces after one month's healing. J Biomech. 2003;36(8):1209-14.

39. Ayali A, Bilginaylar K. Evaluating the biomechanical effects of implant diameter in case of facial trauma to an edentulous atrophic mandible: A 3D finite element analysis. Head Face Med. 2017;13(1):1-7.

40. Kan B, Coskunses FM, Mutlu I, Ugur L, Meral DG. Effects of inter-implant distance and implant length on the response to frontal traumatic force of two anterior implants in an atrophic mandible: Three-dimensional finite element analysis. Int $\mathrm{J}$ Oral Maxillofac Surg [Internet]. 2015;44(7):908-13. Available from: http://dx.doi.org/10.1016/j.ijom.2015.03.002 